\title{
An intern's case study analysis of the patient transport function
}

\author{
Asa B. Wilson*1, Zachary Wilkerson², Leanne Dickinson ${ }^{2}$, Caitlin M. Young ${ }^{1}$ \\ ${ }^{1}$ Healthcare Administration Department, Methodist University, Fayetteville, NC, United States \\ ${ }^{2}$ Patient Transport Department, Cape Fear Valley Health System, Fayetteville, NC, United States
}

Received: October 18, 2019

Accepted: November 11, $2019 \quad$ Online Published: November 20, 2019

DOI: $10.5430 /$ jha.v9n1p11

URL: https://doi.org/10.5430/jha.v9n1p11

\begin{abstract}
Study provides an understanding of a hospital's patient transportation department (PTD) and its essential function within a complex health care system. A participant-observer case study was accomplished using an intern's extended exposure to first-hand interactions with managers, directors, and employees. The narrative delineates the importance of patient transportation in a large, expanding, fast-paced integrated delivery system; an environment requiring daily vigilance, continuous improvement, strategic positioning, innovation, and anticipation of future service needs. The departmental challenges and benefits of a facility-wide transition to a new electronic health information system are specified. The intern's insights into the strategies and data sources that leadership uses to ensure departmental operating effectiveness are identified. Future PTD operations research opportunities are summarized.
\end{abstract}

Key Words: Patient transport, Patient satisfaction, Organizational efficiency, Performance improvement

\section{INTRODUCTION}

Hospitals are unique organizations because, as an adjunct to efficiency, information and patients must flow smoothly, safely, and effectively throughout the physical plant. Further, as hospital-driven mergers and acquisitions intensify, health systems have emerged with expanded building and ground. ${ }^{[1]}$ In response, strategically placed fiber optic cable, adopted software, and hardware ensure a reliable flow of essential information throughout the facility. However, an enlarged plant size, more often than not, increases the distance between patients and key patient support, diagnostic, and therapeutic areas - not everything is immediately available at the bedside in these expanding integrated delivery systems.

As building size expands, the scope and value of patient transport's role dramatically increases. Heretofore, this function was not well respected, was often done by other hospital staff, or was fulfilled by an individual seemingly not otherwise occupied. This traditional positioning within a hospital allowed transport to be primarily an admission or discharge function; one that prevented patients from falling during admission and discharge; reducing risk to facility and patients.

Further, the dynamism of hospital mergers and acquisitions has fostered the patient transport evolution from a decentralized to a centralized function housed in a transport department; thereby creating a support service with standardized monitors and performance expectations. The established department's organizational behavior is augmented by welldefined responsibilities and clear standards of transport care. This transition provided an opportunity to elevate the transport function by defining and documenting it as a key con-

*Correspondence: Asa B. Wilson; Email: awilson@methodist.edu; Address: Healthcare Administration Department, Methodist University, Fayetteville, NC, United States. 
tributor to facility operations.

Heretofore, patient transport studies focused on Emergency Medical Service (EMS) moving emergent patients among levels of care or across treatment settings. ${ }^{[2]}$ Recent studies address patient flow efficiencies within emergency departments. ${ }^{[3-5]}$ It is difficult to find research on patient flow embedded in a large acute care hospital or integrated delivery system (IDS). In addition, the intra-hospital patient transport literature is focused primarily on ensuring the ergonomic safety of transport staff and wellbeing of transported patients.

The purpose of this study is to summarize a health administration intern's participant-observer experiences and data exposure lessons acquired in a large, horizontally expanded heath system's Patient Transport Department (PTD). This information, in turn, is used to discuss the transport function's communication, workflow throughput, patient satisfaction, and organizational efficiency role plus identify future department operations and research opportunities.

\section{CaSe STUdy SetTing}

The case study involved the confluence of three organizational settings: 1) A university's health care administration department, 2) A regional integrated delivery system, and 3) A PTD in the IDS's flagship hospital. Each of these elements are described as follows:

\subsection{Internship description}

A 200-hour health care administration (HCA) internship is a course requirement of an undergraduate program housed in a private university's school of health sciences. The HCA program is an Association of University Programs in Health Administration (AUPHA) certified curriculum. The internship is an experiential learning opportunity supervised conjointly by a faculty member and facility site preceptors. In addition to on-site service hours, each intern is required to complete a project, which: 1) supports the placement site's research-information needs, 2) has applied administrative implications, 3) leads to a written summary analysis, and 4) culminates in a Power Point presentation to a facility audience. An internship's overarching goal is to serve as an experiential learning bridge from the classroom to the workplace or graduate school. ${ }^{[6]}$ Since the university has a long-standing relationship with the participating health facility, the intern was placed in the PTD and spent one week in Environmental Services to gain exposure to another department.

\subsection{Internship organization}

The site organization is a regional health system comprised of 8 hospitals, 7,300 employees, and a medical staff of 850 with joint ventures and outreach services in nine counties. The system is anchored by a 524-bed flagship hospital in a primary service area of 500,000. Residency programs in Internal Medicine, Emergency Medicine, Transitional Care, General Surgery, Ob/Gyn, and Psychiatry are part of the system. In addition, the IDS is home to an institute for clinical research with involvement in a growing number of clinical trials. Hospital statistics from 2015 through 2018 show significant increases in admissions, surgeries, clinic visits, oncology visits, and Emergency Department (ED) visits. The health system's strategy of continuous growth and expanded services requires a persistent emphasis on patient service, customer satisfaction, and measured operational efficiency.

\subsection{Transport department and mission}

"The mission of the PTD is to transport the right patient, at the right time, to the right place, with the right equipment, in the right uniform ... The department is centralized and provides transport support to all areas within the medical center. Transporters also distribute oxygen used for patient care needs. The department is responsible for maintaining all transport devices to include: 1) stretchers, 2) wheelchairs, and 3) transcarts." This mission is governed by well-defined standards of patient transport care that maximize patient safety throughout the transport throughput experience.

Two co-managers supervise the department and are collectively responsible for day-to-day, budgetary, and strategic aspects of the department. One manager supervises daily operations while the other oversees the staff training function. Both managers report to the corporate director patient transport who, in turn, reports to a vice president. The job description for the training manager and operations manager are quite detailed. Both positions require a bachelor's degree in business management or a related field and prior management experience. The operations manager defines goals for the department, interprets patient satisfaction reports, analyzes financial reports, and directly supervises employees. The training manager designs an effective training program with the corporate director, identifies problems and trends, interprets courtesy scores, monitors financial reports, and patient satisfaction results.

\subsection{Transport performance assessment data sources}

Table 1 summarizes the department's primary sources of performance monitoring detail and the way this information is used. The first two reports provide quantitative information derived from direct service transport activities. The remaining three reports, individually and collectively, enable managers to track and assess the interpersonal impact of transport services on patients and staff. These five sources enable the managers to assess performance and identify opportunities for continuous improvement. 
Table 1. PTD performance data sources

\begin{tabular}{|c|c|c|}
\hline No. & Data Source & Detail Provided \\
\hline 1. & Transport Activity Report & $\begin{array}{l}\text { Reports all activities completed by PTD staff. Results can be partitioned by } \\
\text { periods, departments, transporter, and hospital. Monitors are used primarily } \\
\text { for auditing purposes. }\end{array}$ \\
\hline 2. & Transport Productivity Report & $\begin{array}{l}\text { Detailed view of how efficient each transporter is performing as well as a } \\
\text { summary of all the transporter's productivity. This report primarily serves as } \\
\text { an evaluation tool. }\end{array}$ \\
\hline 3. & Press Ganey Patient Satisfaction Survey & $\begin{array}{l}\text { Measures aspects of patient satisfaction. Survey questions designed to } \\
\text { capture results that are department-specific throughout the hospital. }\end{array}$ \\
\hline 4. & $\begin{array}{l}\text { Hospital Consumer Assessment of Healthcare } \\
\text { Providers and Systems Survey (HCAHPS) }\end{array}$ & $\begin{array}{l}\text { A } 27 \text {-item questionnaire assesses patients' experience with key aspects of the } \\
\text { hospital stay, e.g., physician and nurse communication; hospital } \\
\text { environment; medication information; discharge planning; pain } \\
\text { management; global satisfaction. Results track patient experiences with PTD } \\
\text { staff and services. }\end{array}$ \\
\hline 5. & Gallup Employee Survey & $\begin{array}{l}\text { Survey assesses level of employee engagement. Engagement outcomes are } \\
\text { used as a buffer against potential employee disengagement; viewed as a risk } \\
\text { to the facility's interpersonal mission with all customer groups. }\end{array}$ \\
\hline
\end{tabular}

During the internship, the facility transitioned to the EPIC electronic health record (EHR) platform. This transition was augmented by the iPhone ROVER application that replaces pagers enabling orders and jobs to be sent directly to staff; a change that facilitates operating efficiencies. By report, the EPIC transition generated the following outcomes for the patient transportation department (PTD):

- Significantly reduced potential patient identification errors.

- Improved response time.

- Allowed users to enter patient specific comments for transporters to see.

- Drastically improved communication between staff and leadership.

- Ensured fairness when assigning patients to transporters.

- Increased specificity and comprehensiveness of reporting.

- Fostered leadership's ability to monitor real-time patient flow at all facilities.

\section{DISCUSSION - LESSONS LEARNED}

This section identifies the experiential learning value of an intern's extended exposure to the transport function in large, competitive, and growing IDS. An effort has been made to capture the intern's voice in sections of this discussion. In addition, the intern's reflections, in turn, provide guidance for identifying performance improvement opportunities and needed research that supports future operating efficiencies. An intern's experiential learning opportunities and the preceptor's mentoring resulted in an understanding of the DPT's role within a large inpatient center. Those lessons learned and their resultant opportunities are discussed as follows.

In addition, von Elmback, School, and Walter have captured the nature and extent of emerging pressures on in-patient ancillary services: ${ }^{[7]}$

"The rising demographic trend and subsequent increases in health care cost seen in industrial countries are placing ever more pressure on hospitals to be more efficient with their resources. Furthermore, accounting methods, like the Diagnosis Related Groups require that hospitals do not keep patients longer than necessary ... as well as manage their resources economically without decreasing the service quality. As a result of this cost pressure, physicians, nurses and other health care workers find themselves under an increasing workload which leads to increased physical stress and ergonomic burden" (p. 840).

As a result, the transport service is directly impacted by such pressures and must continuously position itself to exceed performance expectations of its constituents.

\subsection{Interpersonal impact of the transport experience}

The transport service stands as one buffer against the challenge of patient flow throughput within the organization. Time spent with the PTD staff confirmed the function's essential support role for therapeutic, diagnostic, and patient-flow demands. Not only do transporters of patients facilitate the movement within the hospital, they also provide a "breath of fresh air" in the form of positive, encouraging patient interaction. Press Ganey Patient Satisfaction Survey results capture patient feedback about the interpersonal feel of the transport 
experience. Consistent high scores are accomplished by designing and training staff about approaches to meeting or exceeding patient expectations. Because the PTD is centralized, its staff and service directly affect facility personnel from a range of departments, especially Imaging Services Radiology and the Emergency Department. The compelling lesson learned is the extent to which PTD staff have unending daily opportunities to foster positive patient and staff experiences via communication.

\subsection{Transport staff training and development}

Transport staff have professional designations such as Certified Healthcare Transporter (CHT) and entry-level Patient Transporter. Impact Training Corporation (ITC) has, since 2003, partnered with the National Association of Healthcare Transport Management (NAHTM) in developing a transporter training curriculum of national standards for certifying healthcare transporters. Professional status is accomplished also by requiring a supervisor to have a high school diploma or GED equivalent with preferences for an associate's degree and one-year of patient transport experience. The CHT designation requires a high-school diploma or GED equivalent with one year of transport experience. Also, a CHT must complete the National Certification Program of Healthcare Patient Transporter. In addition, Transporters must meet training requirements in CPR for Healthcare Providers and Non-violent Crisis Intervention (NCI) within six months of hire.

All staff are encouraged to pursue on-going professional development opportunities. Within the PTD, Transporters have opportunities for growth and advancement. A Transporter may serve as a Trainer Preceptor for new PTD employees after attending the Train-the-Trainer program. This ensures patient quality, safety and continuity of protocol and processes. A Transporter may be promoted to Lead Transporter and serve as the acting Supervisor on weekends. A next step is promotion to a Supervisor. The Icon Infection Control Auditor is another advancement opportunity that allows Transporters to serve as silent hand hygiene inspectors in real-time. Thus, each PTD staff member has well-defined opportunities to expand their role through a combination of continuing education and day-to-day performance excellence. This dynamic is strengthened by seeking additional skill enhancements. For example, if Transporters receive Basic Dysrhythmia training, it would be possible to eliminate requiring a nurse to accompany a transport because then the Transporter would be responsible for detecting and monitoring abnormal heart rhythms.

A core lesson learned is that transport staff face increasing performance expectations from an array of facility con- stituents. In addition, responsibilities for patient welfare are intensifying, especially in high-volume times. Both managers and transporters confront the need to expand training opportunities and skill development outcomes - all accomplished while enhancing the PTD's professional standing organization wide.

\subsection{Assessing operational performance}

The department's activity is measured in terms of jobs accomplished in units of time; defining one completed transport as one job. This operational definition is expanded using key performance indicators (KPI) and expected times for completing specific types of transports. Table 2 summarizes the performance expectations for each type of transport job.

Table 2. PTD key performance indicators

\begin{tabular}{ll}
\hline Transport Type & Time/Volume Standard \\
\hline Discharge & 15 minutes or less \\
ED-to-Observation & Equal to or less than 18 minutes \\
ED-to-Room & Equal to or less than 18 minutes \\
Room-to-Room & 20 minutes or less \\
Jobs per 8-hour shift & 2.5 jobs per hour \\
High performance per 8-hour shift & 3.0 jobs per hour \\
Per-month volume of jobs & 23,000 to 28,000 \\
\hline
\end{tabular}

In practice, these performance expectations are consistent across the specific drivers of facility demands for transport jobs. The following drivers are considered in terms of their capacity to define expected staffing needs as aligned with service volume.

Table 3 summarizes the primary drivers of transport volume and service demands. This information underscores the nature and extent to which the transport function is mission essential as a round-the-clock driver of patient flow.

\subsection{Continuous improvement opportunities}

The transport function has a precise operational definition of performance; one that is readily measured in units of minutes consumed per transport job. As such, the transport function is a perfect candidate for performance improvement monitoring and interventions. Lean and statistical process control (SPC) applications can be used to identify throughput issues and performance improvement opportunities. The student's success as an intern stimulated an understanding of how future interns can engage in research projects and execute continuous improvement tactics. The following is a list of areas for future involvement:

- Education and experience with Kaizen projects and LEAN methodology.

- Key Performance Indicator auditing. 
- SBARR monitoring and analyzing.

- Simulation lab training.

- Employee engagement suggestions.

- Exposure to Management Forums and committee meetings.

- Policy updates and change managements.

- Personnel issues and counseling training.

There is no escaping that fulfilling the PTD's mission is a daily logistic challenge, especially in a large facility with an extensive scope of patient services. As such, day-to-day operating demands and quantitative assessment tools provide enduring opportunities for intern training and operational assessments. ${ }^{[8-12]}$

A lesson learned is the essential nature of quantitative assessment via performance monitoring while using data to identify needed interventions. The department's core job-assessed in time to complete and volume of jobs accomplished per shift provides a rich datum inventory encouraging an array of Lean and Six Sigma quality improvement activities. Equally exciting is the availability of the department's patient satisfaction scores and budget detail; an information mix that enables assessing and reporting the value of transport services. Here, value is defined as "patient transport throughput outcomes achieved per dollar spent". ${ }^{[13,14]}$

Table 3. Drivers of PTD service demands

\begin{tabular}{|c|c|}
\hline Job Driver & Service Demand Impact \\
\hline Emergency Department Queuing & $\begin{array}{l}\text { - Patient flow begins primarily in the ED. Admissions always have high priority. } \\
\text { - Critical and Step-Down patients prioritized as "Stat". } \\
\text { - Patients "holding" in the ED waiting room create a bottleneck hindering patient } \\
\text { flow. To alleviate delays in patient throughput movement additional PTD staff are } \\
\text { added. } \\
\text { - ED has a designated transporter for first and second shift. This person transports } \\
\text { patients to and from the ED to Radiology. This staff allocation expedites diagnostic } \\
\text { testing. }\end{array}$ \\
\hline Ancillary Department Procedures & $\begin{array}{l}\text { - We plan for a greater volume of requests from ancillary departments on Fridays and } \\
\text { Mondays due to reduced hospital-wide weekend capacity. } \\
\text { - When transport leadership is informed of staffing challenges faced by ancillary } \\
\text { departments, we will adjust scheduling and priority assignment to help reduce } \\
\text { potential delays in patient care. }\end{array}$ \\
\hline ED Waiting Room Queuing & $\begin{array}{l}\text { - Patients in the waiting room usually indicate a bottleneck or potential saturation. } \\
\text { This will then drive admissions, which then drives discharges on the acute side. Both } \\
\text { discharges and admissions will be equally prioritized, and staffing is adjusted } \\
\text { accordingly. Ancillary departments requesting patients could be delayed if staffing } \\
\text { adjustments are not made. }\end{array}$ \\
\hline Patient Acuity Fluctuations & $\begin{array}{l}\text { - Patients considered critical/high acuity, who require nurse escorts and monitoring, } \\
\text { are expedited reducing a nurse's off-unit time away from other patients. } \\
\text { - Patients transferring to a higher acuity floor will be highly prioritized due to the } \\
\text { decline in their health. } \\
\text { - Patients transferring out of ICU or stepdown are highly prioritized opening room up } \\
\text { for: 1) potential holds from the ED, 2) holds from other floors, and 3) critical patients } \\
\text { requiring a specific nurse to patient ratio. }\end{array}$ \\
\hline Patient Discharges & - Discharges, as a driver of patient flow, are always categorized high priority. \\
\hline
\end{tabular}

\subsection{Organizational integration}

Though the organization recognizes differing servicedemand conditions (Alpha, Delta, Saturation), the PTD fulfills its mission independent of the organization's everchanging dynamics. Unfortunately, the transport service and its staff are infrequently recognized for their contribution's

Published by Sciedu Press

value or the extent of their patient-service responsibilities and actual professionalism.

Patient Transportation also allows nurses and technicians to focus on patient care because these team members no longer need to spend valuable time conducting transports. In addition to this primary clinical support mission, Trans- 
porters are trained first responders in a potential code situation. They also are knowledgeable about critical drip medications and the need for a nurse escort. Patient Transportation ensures even distribution of Oxygen to allow for adequate availability. Wayfinding for staff and visitors is a synergy the health system recognizes. Another vital clinical support benefit is that transporters are the facilitators for the patient Situation-Background-Assessment-RecommendationResponse (SBARR) results between clinical staff that aids in proper communication and handoff. When the clinical team needs assistance to lift a patient who has fallen or pain tolerance is low, the transport staff is enlisted as a solution. Finally, experience with Patient Transportation is usually the last impression a patient has with staff before being discharged from the hospital.

However, the total organization supports a promoting-fromwithin approach to its staff. Because transporters have daily contact with personnel throughout the health system, these positive exchanges often result in job expansion opportunities or positions in other departments. Invitations to serve on committees are a frequent occurrence. Also, as managing-up pervades the system's interpersonal communication culture, transporters find themselves increasingly identified as key factors in the overall patient care mission.

However, the intern's lesson learned is the reality that the department and its staff, individually and collectively, establish a vibrant interconnectivity among patients, nurses, diagnostic technicians, attending physicians, and therapeutic personnel throughout the organization. Metaphorically, this dynamic has characterized the PTD as the feet of the organization as well as reliable communication network.

\section{Conclusions}

A core lesson learned is that the patient transport role in a large IDS fulfills an important patient flow function; one that must operate efficiently in order to effectively support the hospital's patient-flow demands. This on-going obligation is accomplished by: 1) consistent, positive patient engagement, 2) continuous staff training and development; 3) measured attention to operational performance; 4) identifying and executing continuous improvement adjustments, and 5) maintaining interpersonal sensitivity to executive, operations, and clinical personnel. These leadership initiatives, in turn, provide opportunities to engage interns in research projects that redound to an intern's professional development and the department's enhanced performance.

\section{ACKNOWLEDGEMENTS}

A note of appreciation goes to Dr. Warren McDonald, a facility board officer and university department chair, for creating student internship opportunities. Mr. Kevin Jackson and Dr. Frank Campbell, senior leaders in the case study health center, were supportive of the student's internship and contributed to this project.

\section{CONFLiCTS OF InTEREST Disclosure}

The authors declare they have no conflicts of interest.

\section{REFERENCES}

[1] Postma J, Roos AF. Why health care providers merge. Health Economics, Policy and Law. 2016; 11: 121-140. PMid: 26055501 https://doi.org/10.1017/S1744133115000304

[2] Taylor BN, Rasnake N, McNutt K, et al. Rapid ground transport of trauma patients: A moderate distance from trauma center improves survival. Journal of Surgical Research. 2018;232: 318-324. PMid: 30463735. https://doi.org/10.1016/j.jss.2018.06.055

[3] Silva SL, Figueiredo JMA. Application of a physical science model in the analysis of a patient flow in a hospital. Journal of Hospital Administration. 2019; 8(1): 34-43. https://doi.org/10.5430/ jha.v8n1p34

[4] Garrett JS, Berry S, Wong Q, et al. The effect of vertical splitflow patient management on emergency department throughput efficiency. American Journal of Emergency Medicine. 2019; 36: 15811584. PMid: 29352674. https://doi.org/10.1016/j.ajem.2 018.01 .035

[5] Olwanda E, Shen J, Kahn JG, et al. Comparison of patient flow and provider efficiency of two delivery strategies for HPV-based cervical cancer screening in Western Kenya: A time and motion study. Glob Health Action. 2018; 11(1): 451-455. PMid: 29589991. https://doi.org/10.1080/16549716.2018.1451455
[6] Wilson AB, Nowak AP. Why a health administration internship? Research in Health Science. 2019; 4(3): 142-151. https ://doi .or g/10.22158/rhs.v4n3p142

[7] von Elmbach A, Scholl A, Walter R. Minimizing the maximal ergonomic burden in intra-hospital patient transportation. European Journal of Operational Research. 2019; 276: 840-854. https: //doi.org/10.1016/j.ejor.2019.01.062

[8] Kim S, Barker LM, Jia B, et al. Effects of two hospitals bed design features on physical demands and usability during brake engagement and patient transportation: A repeated measures experimental study. International Journal of Nursing Studies. 2009; 46: 317-325. PMid: 19027904. https://doi.org/10.1016/j.ijnu rstu.2008.10.005

[9] Arthur J. Lean Six Sigma for hospitals. New York, NY: McGraw Hill; 2011.

[10] Hamel LM, Chapman R, Eggly S, et al. Measuring the use of examination room time in oncology clinics: A novel approach to assessing clinic efficiency and patient flow. Journal of Oncology Practice. 2014; 10(6): e385-e389. PMid: 25248723. https: //doi.org/10.1200/JOP. 2013.001359

[11] Krvavac A, Kamel G, Patel PP, et al. Evaluating and improving the efficiency of patient flow in the bronchoscopy suite in a tertiary 
care center. Quality Management in Health Care. 2018; 27(1): 3338. PMid: 29280906. https://doi.org/10.1097/QMH. 000000 0000000155

[12] Nicosia FM, Park LG, Gray CP, et al. Nurses' perspectives on Lean redesigns to patient flow and inpatient discharge process efficiency. Global Qualitative Nursing Research. 2018; 5: 1-10. PMid: 30480041. https://doi.org/10.1177/2333393618810658
[13] Lee TH. Putting the value framework to work. New England Journal of Medicine. 2010; 363(26): 2481-2483. PMid: 21142527. https://doi.org/10.1056/NEJMp1013111

[14] Porter ME. What is value in health care? New England Journal of Medicine. 2010; 363(26): 2477-2481. PMid: 21142528. https://doi.org/10.1056/NEJMp1011024 